\title{
miR-135 regulated breast cancer proliferation and epithelial-mesenchymal transition acts by the Wnt/ $\beta$-catenin signaling pathway
}

\author{
DAQIONG JIANG，BO ZHOU，YAN XIONG and HONGBING CAI
}

Department of Gynecological Oncology, Zhongnan Hospital of Wuhan University, Wuhan, Hubei 430071, P.R. China

Received August 30, 2018; Accepted January 17, 2019

DOI: 10.3892/ijmm.2019.4081

\begin{abstract}
Breast cancer (BC) is the most common cancer in women around the world. microRNAs (miRNAs/miRs) have been proved to be associated with the development and progression of breast cancer. In the present study, to elucidate the effects of dysregulated miR-135 on cells and underlying mechanisms in $\mathrm{BC}$, in vitro and in vivo experiments were conducted. The biological functions of miR-135 were studied using MTT, colony formation, wound healing, transwell assays as well as tumorigenicity analysis. Gain- and loss- of function of miR-135 studies revealed that ectopic expression of miR-135 in MDA-MB-468 and MCF-7 cells significantly inhibited cell growth, migration, invasion and EMT, at least in part through inhibiting the activation of the $\mathrm{Wnt} / \beta$-catenin pathway. Moreover, this was reversed in cells which were transfected with miR-135 inhibitors. Taken together, the results of the present study provided evidence that miR-135 acted as a tumor suppressor in BC, which may represent a novel therapeutic strategy for the diagnosis and prognosis of BC.
\end{abstract}

\section{Introduction}

Breast cancer (BC) is the most commonly diagnosed cancer, which holds the highest mortality rate in women around the world (1-4). It has been documented that radiation therapy and chemotherapy have been employed in treating $\mathrm{BC}$, which can lead to the improvement of prognosis (5). However, chemotherapy resistance and metastasis may lead to failure of $\mathrm{BC}$ therapy (6). BC is a complex disease, which is influenced by several environmental factors and genetic alterations. The environmental factors include unhealthy diet and psychology, environmental contamination and radiation. Gene dysregulation may lead to the spreading of tumor cells from the

Correspondence to: Dr Hongbing Cai, Department of Gynecological Oncology, Zhongnan Hospital of Wuhan University, 169 East Lake Road, Wuhan, Hubei 430071, P.R. China

E-mail: jiangdq_wh@sina.com

Key words: miR-135, proliferation, epithelial-mesenchymal transition, Wnt/ $\beta$-catenin pathway, breast cancer primary neoplasm to distant sites (7). Therefore, it is urgent to gain further insight into the gene expression alterations and molecular mechanism in $\mathrm{BC}$ progression that may aid better therapeutic developments for BC patients.

MicroRNAs (miRNAs/miRs) are small noncoding single-stranded RNA molecule of 20-25 nucleotides in length that regulate gene expression (8). It has been demonstrated that miRNAs function as oncogenes or tumor suppressors and modulate a variety biological processes, including cell proliferation, migration, invasion, metastasis, apoptosis and differentiation (9-13). Dysregulation of several miRNAs has been demonstrated in BC, including miR-122 (14), miR-34a (15) and miR-155 (16), which associated with the development and progression of malignancy. $\mathrm{miR}-135$ has been reported to serve important roles in the development of various types of cancer, including colorectal cancer, non-small cell lung cancer and renal cancer (17-19). It was reported that miR-135 was highly expressed in metastatic breast tumors and promotes cell migration and invasion by targeting HOXA10 (20). Furthermore, a considerable upregulation of miR-135 in colorectal adenomas and carcinomas was observed, which is significantly correlated with low APC mRNA levels and miR-135 serves as a tumor suppressor in breast cancer metastasis (17). In addition, miR-135 inhibits prostate cancer cell growth and migration by targeting the epidermal growth factor receptor (EGFR) (21). However, it remains unclear whether miR-135 is involved in $\mathrm{BC}$ progression. Therefore, the development of novel effective therapeutic strategies is essential and urgent.

It is known that epithelial-mesenchymal transition (EMT) is a complex biological process. Specifically, cells undergoing EMT have increased expression of mesenchymal molecules including snail, slug and vimentin and decreased expression of the epithelial adhesion marker epithelial (E)-cadherin, leading to enhanced motility and metastasis (22). Increasing evidence has demonstrated that aberrant activation of $\mathrm{Wnt} / \beta$-catenin signaling promoted cell proliferation and is associated with poor prognosis of $\mathrm{BC}$ patients (23-25). Aberrant activation of the $W n t / \beta$-catenin signaling pathway is identified and promoted tumor progression in a number of types of human cancer (26-30).

Therefore, miR-135 expression was measured in BC cells and biological functions of miR-135 were investigated in BC. In the present study, it was demonstrated that expression of miR-135 was significantly reduced in BC cells and overex- 
pression of miR-135 inhibited cell proliferation, migration, invasion and metastasis. Finally, it was demonstrated that miR-135 suppression was followed by Wnt/ $\beta$-catenin signaling pathway activation. Collectively, the results of the present study demonstrated that miR-135 suppresses the progression of $\mathrm{BC}$ by regulating the Wnt/ $\beta$-catenin signaling pathway.

\section{Materials and methods}

Cell lines and transfection. Human breast cancer cell lines MDA-MB-468, MDA-MB-231 and normal epithelial cell line MCF-10A were purchased from the Cell Type Culture Collection of the Chinese Academy of Sciences (Shanghai, China) and routinely maintained in RPMI-1640 medium (Gibco; Thermo Fisher Scientific, Inc., Waltham, MA, USA) with $10 \%$ fetal bovine serum (FBS; Gibco; Thermo Fisher Scientific, Inc.) and human breast cancer cell line MCF-7 was cultured in RPMI 1640 medium. All cells were incubated in a humidified $5 \% \mathrm{CO}_{2}$ atmosphere at $37^{\circ} \mathrm{C}$. The miR-135 mimic, miR-135 inhibitor or scrambled miRNA control which expressed green fluorescent protein (GFP) were transfected to the MDA-MB-468 and MCF-7 cells with Lipofectamine 2000 (Invitrogen; Thermo Fisher Scientific, Inc.) according to the manufacturer's protocol. The sequences were as follows: miR-135 mimic forward, 5'-UAUGGCUUUUCAUUCCUA UGUGA-3' and reverse, 5'-ACAUAGGAAUGAAAAGCC AUAUU-3'; miR-135 inhibitor forward, 5'-UCACAUAGGAAU GAAAAGCCAUA-3' and reverse, 5'-CAGUACUUUUGU GUAGUACAA-3'; and scrambled miRNA control forward, 5'-UUCUCCGAACGUGUCACGUTT-3' and reverse, 5'-ACG UGACACGUUCGGAGAATT-3'. A total of 2 days later, cells were collected and stored at $-80^{\circ} \mathrm{C}$.

RNA extraction and quantitative polymerase chain reaction $(q P C R)$. Total RNA was extracted from cell lines using TRIzol reagent (Invitrogen; Thermo Fisher Scientific, Inc.) according to the manufacturer's protocol. TaqMan MicroRNA Reverse Transcription kit (Takara Bio, Inc., Otsu, Japan) was used to synthesize cDNA from total RNA at $37^{\circ} \mathrm{C}$ for $30 \mathrm{~min}$. qPCR was performed on an Applied Biosystems StepOne Plus Real-Time PCR System (Takara Bio, Inc., Otsu, Japan). The PCR conditions consisted of $95^{\circ} \mathrm{C}$ for $30 \mathrm{sec}$, followed by 40 cycles of amplification $\left(95^{\circ} \mathrm{C}\right.$ for $3 \mathrm{sec}$ and $60^{\circ} \mathrm{C}$ for $30 \mathrm{sec}$ ). The primer sequences were as follows: miR-135 forward, 5'-TCTGCTGTGGCCTATGGCTT-3', reverse, 5'-CTGTAG CCCATGGCTTTTAGC-3' and U6 forward, 5'-CTCGCT TCGGCAGCACA-3', reverse, 5'-AACGCTTCACGAATT TGCGT-3'. The small nuclear RNA U6 was used as control. Fold-changes for mRNA expressions were calculated using the $2^{-\Delta \Delta \mathrm{Cq}}$ method (31) and all experiments were performed in at least triplicate.

Western blot analysis. For western blot analysis, total protein was extracted from transfected cells using radioimmunoprecipitation assay (RIPA) buffer (Beijing Solarbio Science \& Technology Co., Ltd., Beijing, China) and the supernatants were collected with centrifugation at $12,000 \mathrm{x} \mathrm{g}$ at $4^{\circ} \mathrm{C}$ for $20 \mathrm{~min}$. Protein concentration was measured with a Bicinchoninic acid Protein Assay kit (Beyotime Institute of Biotechnology, Haimen, China). Subsequently, equal amounts of protein
(30 $\mu \mathrm{g}$ ) from each sample were separated by $10 \%$ SDS-PAGE and transferred onto polyvinylidene difluoride membranes. The membranes were blocked with $5 \%$ non-fat milk for $1 \mathrm{~h}$ at room temperature and then incubated with primary antibodies overnight at $4^{\circ} \mathrm{C}$. The specific primary antibodies were as follows: Anti-wnt (ab15251; 1:1,000; Abcam, Cambridge, UK), p-GSK3 (ab75745; 1:1,000; Abcam), GSK3 (ab32391; $1: 1,000$; Abcam), $\beta$-catenin (ab32572; 1:1,000; Abcam). Following the membranes were washed with TBST containing $0.2 \%$ Tween-20 three times and incubated with the horseradish peroxidase-conjugated anti-rabbit secondary antibody (cat. no. ab6721; 1:2,000; Abcam) at room temperature for $1 \mathrm{~h}$. The blot was visualized by an odyssey infrared imaging system with ECL western blotting substrate kit (Amersham; GE Healthcare, Chicago, IL, USA). Expression of GAPDH was used as a loading control.

Cell proliferation colony formation assay. Cell proliferation was measured by the MTT assay (Nanjing KeyGEN Biotech, Co., Ltd., Nanjing, China). MDA-MB-468 and MCF-7 cells (1.0x $10^{4} /$ well) were plated in a 6 -well plate and transfected with miR-135 mimics, miR-135 mimics negative control (NC), miR-135 inhibitors and miR-135 inhibitors NC. At 24, 48 and 72 h of incubation, cells were washed with PBS, and dimethyl sulfoxide used to dissolve the purple formazan. Then, $20 \mu \mathrm{l}$ MTT were added into each well for $4 \mathrm{~h}$. The absorbance of the resulting solution was assessed at $490 \mathrm{~nm}$ wavelength with a microplate reader (BioTek Instruments, Inc., Winooski, VT, USA). For colony formation assay, cells were subcultured in a 6-well plate for 2 weeks. The cells were washed twice with PBS, fixed in $4 \%$ paraformaldehyde at room temperature for $30 \mathrm{~min}$ and stained with $5 \%$ crystal violet for $4 \mathrm{~h}$ at room temperature, and counted under a light microscope.

Wound healing assay. For the wound healing assay, MDA-MB-468 and MCF-7 were seeded into 6-well plates at density of $1 \times 10^{5}$ cells per well following transfection and cultured in fresh culture the confluence reached $90 \%$. Furthermore, sterile pipette tips was used to scratch the wound uniformly and incubated at $37^{\circ} \mathrm{C}$ for 0,24 and $48 \mathrm{~h}$. The cell migration ability was assessed using a light microscope and images were captured at 0,24 and $48 \mathrm{~h}$ following scraping. Each experiment was conducted in triplicate.

Transwell assay. The migration and invasion of transfected MDA-MB-468 and MCF-7 cells were evaluated by using Boyden chambers consisting of transwell with $8-\mu \mathrm{m}$ pore size polycarbonate membrane filters. For migration assay, cells were plated at a density of $2 \times 10^{5}$ cells/well in the upper chamber of a transwell filter. For invasion assay, matrigel was added to the inner surface. Cells were placed in RPMI-1640 medium on the top chamber and the lower chambers were filled with RPMI-1640 medium supplemented with 10\% FBS. After incubation for $48 \mathrm{~h}$, nonmigrated or noninvasive cells on the upper surface were removed carefully with a cotton swab. The cells bound to the lower side of the filter were washed twice with PBS and fixed with 5\% gluteraldehyde at room temperature for $10 \mathrm{~min}$. Fixed cells were washed twice with PBS and fixed $4 \%$ paraformaldehyde for $30 \mathrm{~min}$ at room temperature. After that, cells were stained with $0.1 \%$ crystal 
A

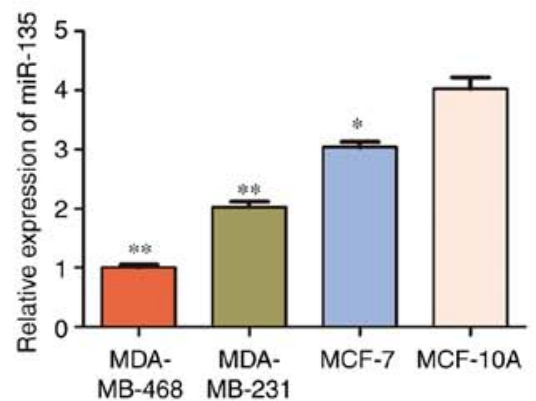

B

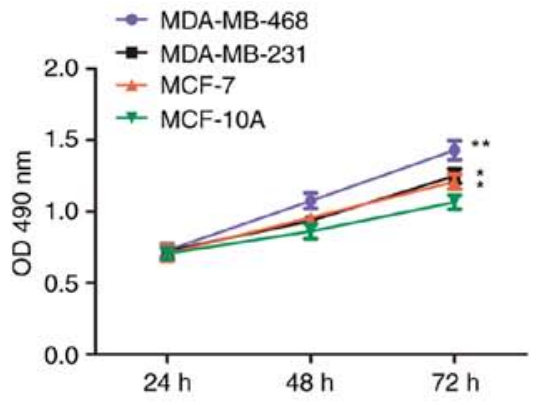

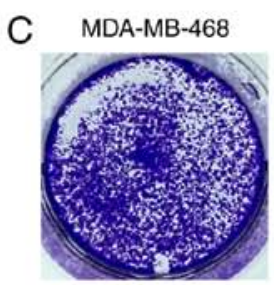

MDA-MB-231
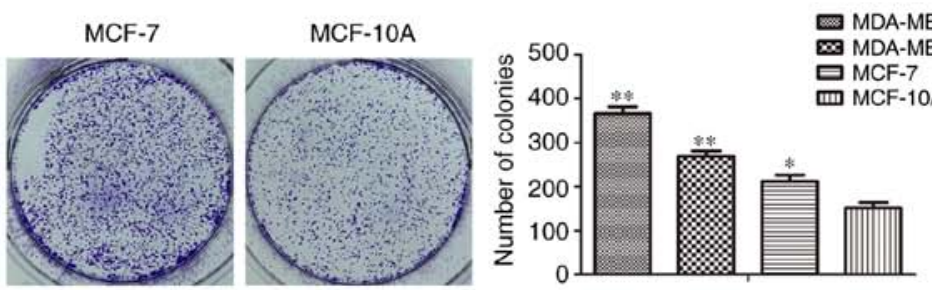

D
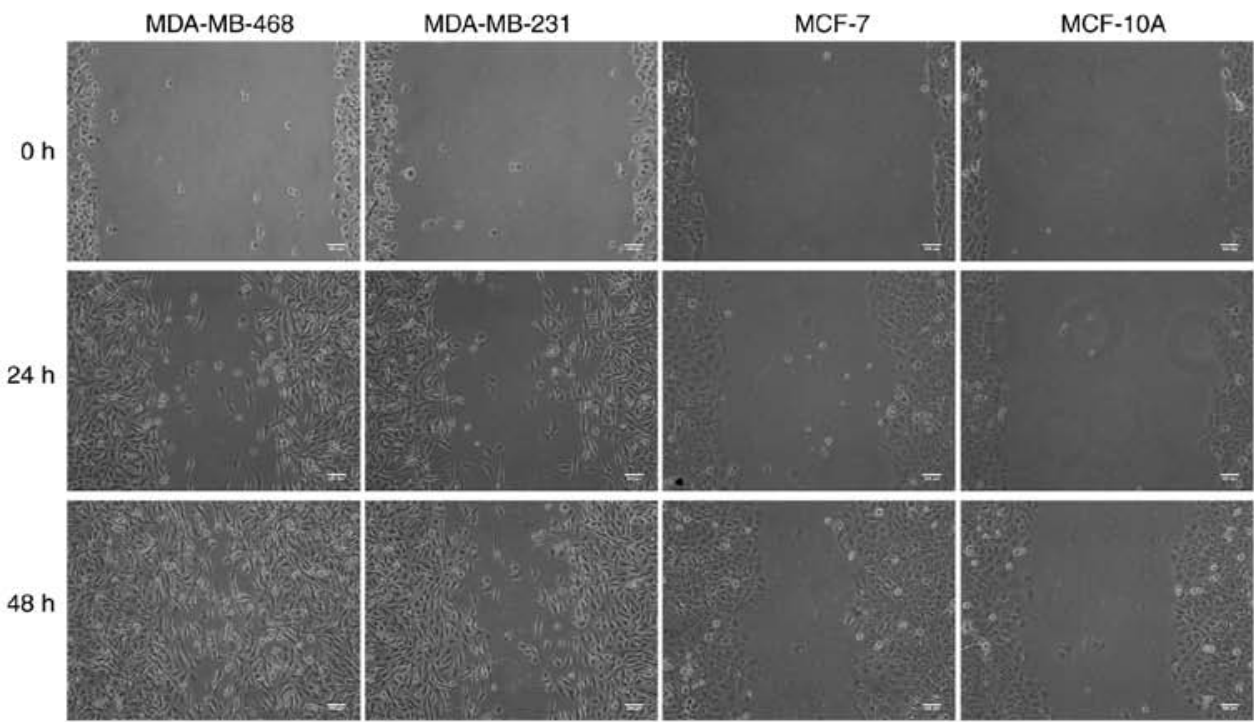

E

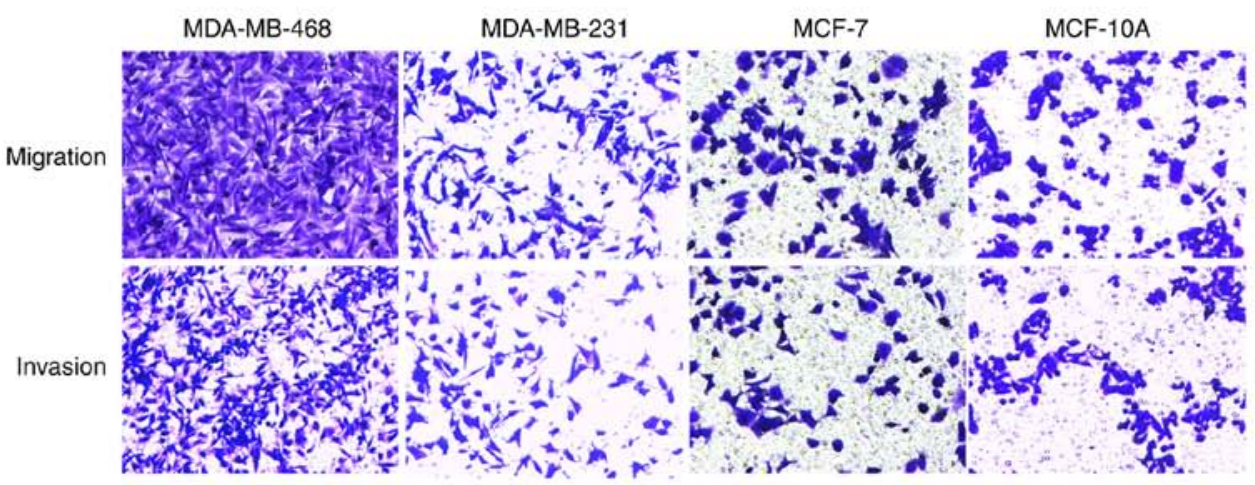

Figure 1. miR-135 is downregulated in BC cell lines. (A) miR-135 expression in BC cell lines and a normal breast epithelium cell line were examined by reverse transcription-quantitative polymerase chain reaction. The proliferation of cells was determined by (B) MTT and (C) colony formation assay. Effects of miR-135 on (D) cell migration and (E) invasion in cells. ${ }^{*} \mathrm{P}<0.05$ and ${ }^{* *} \mathrm{P}<0.01$ vs. MCF-10A cell lines. miR, microRNA; BC, breast cancer; OD, optical density.

violet for another $30 \mathrm{~min}$ at room temperature. The migration and invasion cells were counted and imaged in six random fields under a light microscope at x200 magnification.

Immunofluorescence assay. Cells $\left(1 \times 10^{5}\right)$ were seeded on 6-well plates and incubated for $48 \mathrm{~h}$. After that, MDA-MB-468 and MCF-7 cells were fixed with $4 \%$ paraformaldehyde for $30 \mathrm{~min}$ at room temperature and incubated with the primary antibodies at room temperature for $2 \mathrm{~h}$ after blocking cell with $3 \%$ bovine serum albumin (Gibco; Thermo Fisher Scientific, Inc.). The specific primary antibodies are as follows: Anti-wnt (ab15251; 1:1,000; Abcam), p-GSK3 (ab75745; 
A

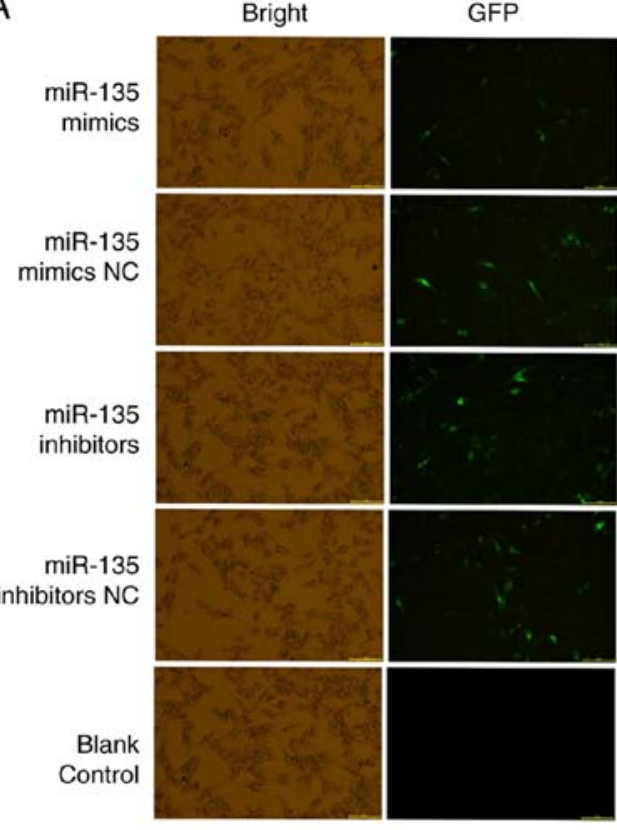

MDA-MB-468

B

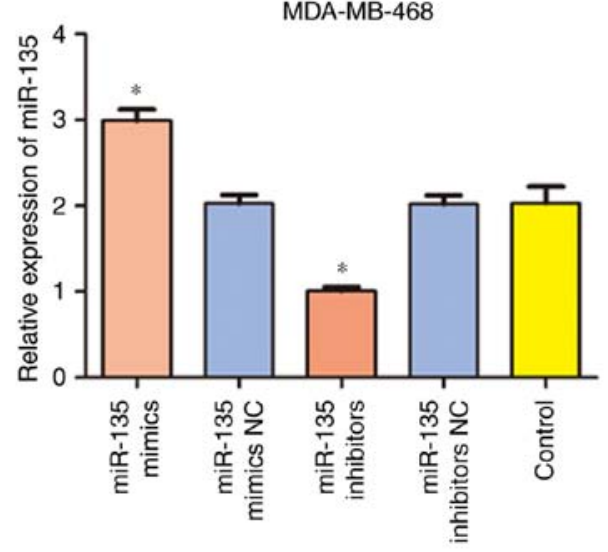

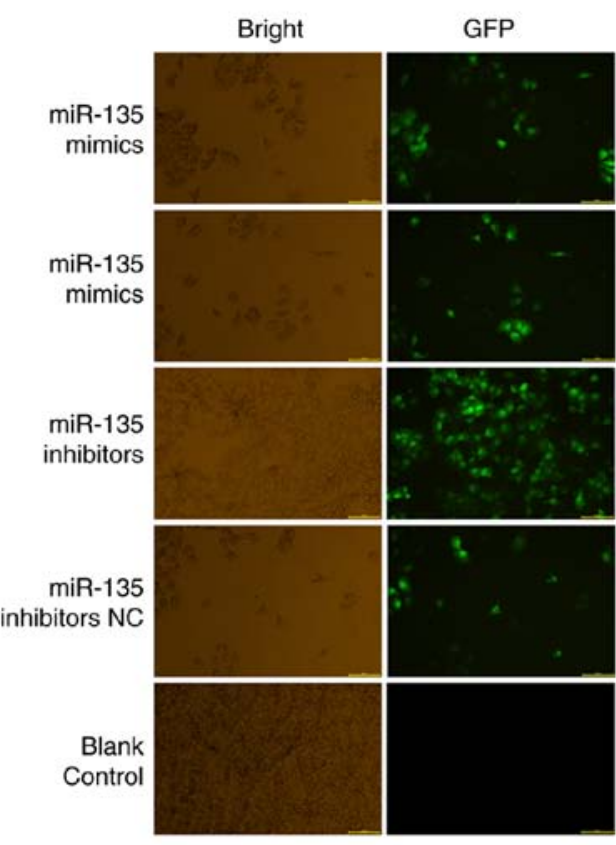

MCF-7

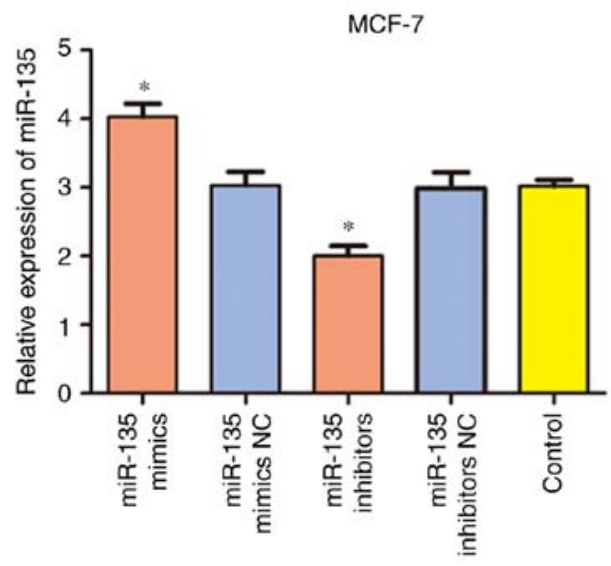

$\rightarrow$ miR-135 mimics

*- miR-135 mimics NC

$2.0 \rightarrow$ miR-135 inhibitors

$\rightarrow$ miR-135 inhibitors NC

$\varepsilon^{1.5-\rightarrow \text { Blank control }}$

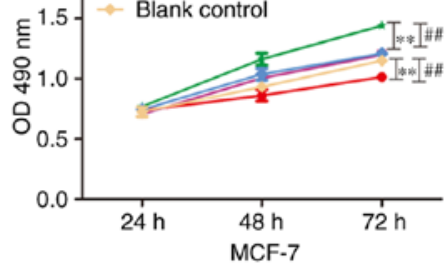

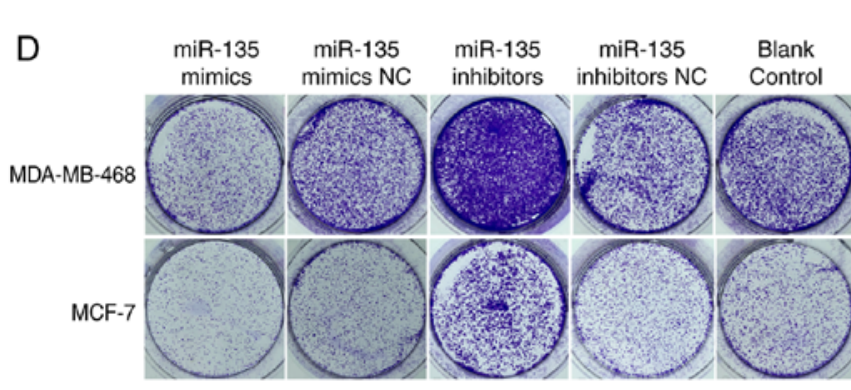

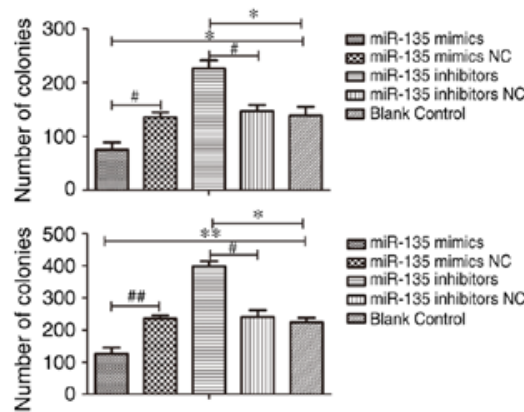

Figure 2. miR-135 inhibits cell proliferation. Following transfection with miR-135 mimics or miR-135 inhibitors in (A) MDA-MB-468 and (B) MCF-7 cells, the transfection efficiency was detected by reverse transcription-quantitative polymerase chain reaction. The proliferation of cells was determined by (C) MTT and (D) colony formation assay. The results were expressed as the mean \pm standard deviation of three independent experiments. ${ }^{*} \mathrm{P}<0.05$ and ${ }^{* *} \mathrm{P}<0.01 \mathrm{vs}$. control group. ${ }^{\#} \mathrm{P}<0.05$ and ${ }^{\# \#} \mathrm{P}<0.01$ vs. NC group. NC, negative control; miR, microRNA; OD, optical density; GFP, green fluorescent protein. 

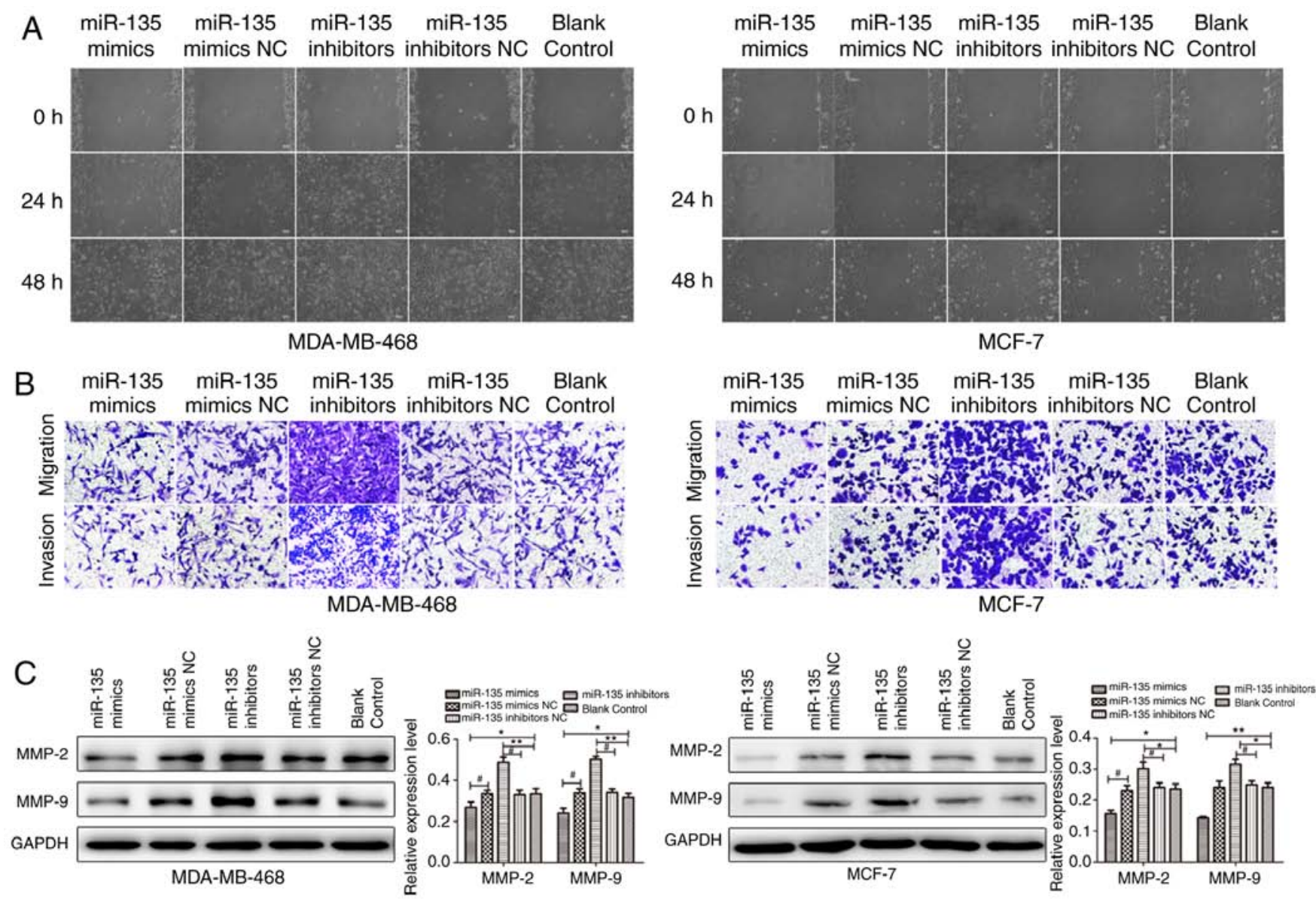

Figure 3. miR-135 suppresses migration and invasion in breast cancer cells. (A) The migration abilities of MDA-MB-468 and MCF-7 cells transfected with miR-135 mimics or miR-135 inhibitors for $48 \mathrm{~h}$ were examined by wound healing assay. (B) The of migratory and invasive abilities in MDA-MB-468 and MCF-7 cells were evaluated using a transwell invasion assay. (C) Expression levels of the MMP-2 and MMP-9 proteins were determined by western blot assay. " $\mathrm{P}<0.05$ and ${ }^{* *} \mathrm{P}<0.01$ vs. control group. ${ }^{\#} \mathrm{P}<0.05$ vs. $\mathrm{NC}$ group. miR, microRNA; $\mathrm{BC}$, breast cancer; MMP, matrix metalloproteinase.

1:1,000; Abcam), GSK3 (ab32391; 1:1,000; Abcam), $\beta$-catenin (ab32572; 1:1,000; Abcam). Thereafter, an Alexa Fluor 594-Conjugated Anti-Rabbit IgG (H+L) (SA00006-4; 1:1,000; ProteinTech Group, Inc., Chicago, IL, USA) second antibody was incubated for $1 \mathrm{~h}$ at room temperature. The nuclei were counterstained with DAPI for $5 \mathrm{~min}$ at room temperature. The slides were examined under a confocal microscopy.

Xenografted tumor model. A total of 30 female nude mice ( 6 weeks old, 18-22 g) were provided by the Nanjing Medical University and housed under germ free conditions. Animal care and use were carried out according to the ethical guidelines by Nanjing Medical University Animal Care and Use Committee and approved by the Nanjing Medial University Experimental Animal Ethics Committee and the permit number is SYXK(su)2016-0016. Mice were maintained in laminar airflow chambers under specific pathogen-free conditions in a temperature controlled room $\left(24^{\circ} \mathrm{C}\right)$ under a $12 \mathrm{~h}$ light/dark cycle. They were provided free access to water and standard laboratory rodent chow. MCF-7 cells $\left(5 \times 10^{6}\right)$ transfected with an miR-135 mimic, miR-135 inhibitor or the control vector were inoculated subcutaneously into the right flanks of nude mice, respectively. The volume of tumor was measured every week and calculated using the equation volume $\left(\mathrm{mm}^{3}\right)=$ length $\mathrm{x}(\text { width })^{2} / 2$. After five weeks, the mice were sacrificed by cervical dislocation and stored in $-80^{\circ} \mathrm{C}$ for further use. In addition, xenografted tumor tissue samples were obtained and were fixed in formalin for $24 \mathrm{~h}$ at room temperature and embedded in paraffin. Hematoxylin and eosin (H\&E) staining was performed to obtain histological samples of the tumor.

$H \& E$ staining. The tumors tissues were fixed in $4 \%$ paraformaldehyde for $30 \mathrm{~min}$ at room temperature and then embedded in paraffin. The $4-\mu \mathrm{m}$ sections were stained with $\mathrm{H} \& \mathrm{E}$ staining for $20 \mathrm{~min}$ at room temperature. At least three different sections of tumor tissues were examined for each group using a light microscope to assess the histopathological changes.

Terminal deoxynucleotidyl-transferase-mediated dUTP nick end labelling (TUNEL) staining. The apoptosis of paraffin-embedded tumor $4-\mu \mathrm{m}$ sections was detected using a TUNEL assay kit. Briefly, fixed and paraffin-embedded sections were dewaxed, then proteinase $\mathrm{K}$ was added into for $20 \mathrm{~min}$ at room temperature. The sections had $3 \% \mathrm{H}_{2} \mathrm{O}_{2}$ added following washing with PBS and then were incubated with the equilibration buffer and terminal deoxynucleotidyl transferase (TdT) enzyme for $1 \mathrm{~h}$ at room temperature in the dark. Sections were treated with $3 \% \mathrm{H}_{2} \mathrm{O}_{2}$ for $5 \mathrm{~min}$ and horseradish peroxi- 

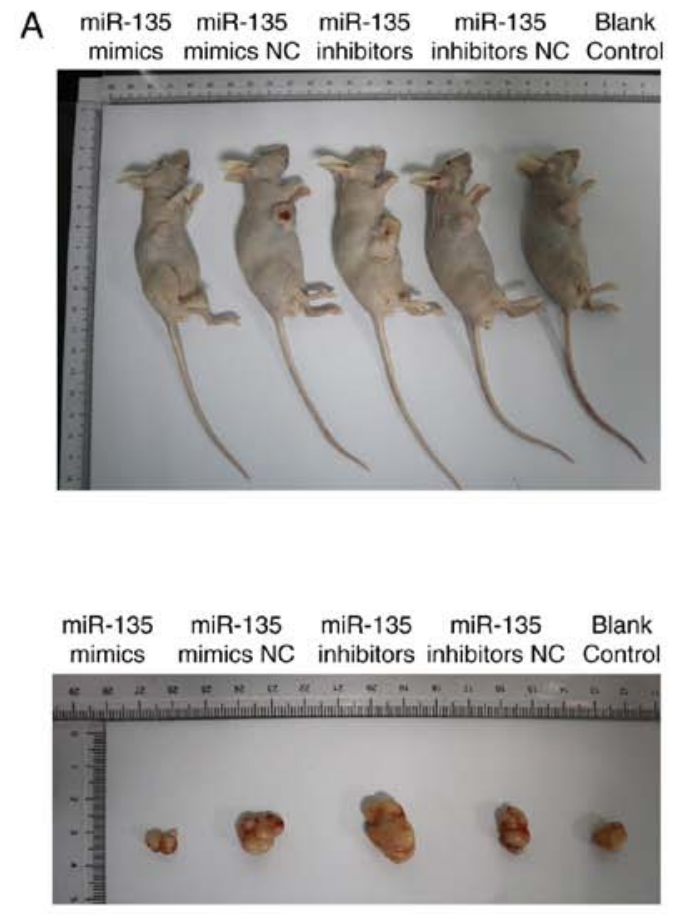

C
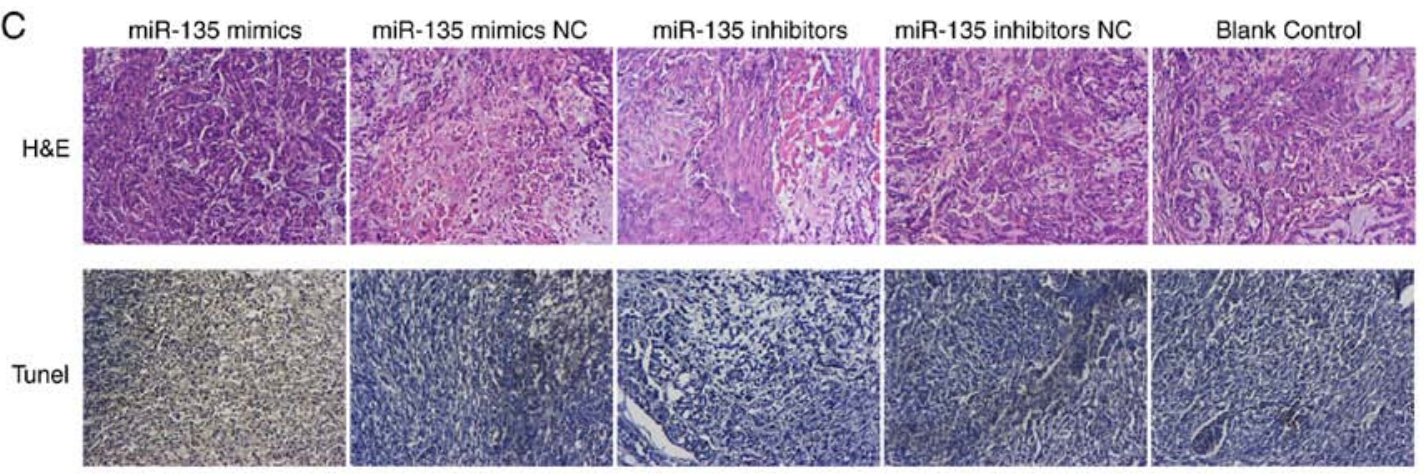

Figure 4. miR-135 inhibits breast cancer tumor growth in vivo. (A) Cells $\left(2 \times 10^{6}\right)$ were injected into the nude mice. After 30 days, the cells stably transfected with miR-135 mimics formed smaller tumors compared with the controls. (B) Mice weight and tumor volumes and weight were measured. (C) H\&E analysis of the pathological features of the tumors and TUNEL assay of apoptosis from the five groups. The data are presented as the mean \pm standard deviation. ${ }^{* *} \mathrm{P}<0.01$ vs. control group. ${ }^{*} \mathrm{P}<0.05$ and ${ }^{\# \#} \mathrm{P}<0.01$ vs. NC group. NC, negative control; miR, microRNA; H\&E, hematoxylin and eosin; TUNEL, terminal deoxynucleotidyl-transferase-mediated dUTP nick end labelling.

dase for 30 min following washing with PBS. Finally, sections were incubated with DAB for $5 \mathrm{~min}$ at room temperature to evaluate the tissue peroxidase activity and five fields per view were analyzed with a light microscope.

Statistical analysis. All data were expressed as the mean \pm standard deviation and statistical analyses were performed with 19.0 SPSS software (IBM, Corp., Armonk, NY, USA); three independent experiments were performed. Statistical analyses of pairs of samples were performed using the Student's t-test. Multiple group comparisons were carried out by one-way analysis of variance with Bonferroni's post-hoc test. $\mathrm{P}<0.01$ was considered to indicate a statistically significant difference.
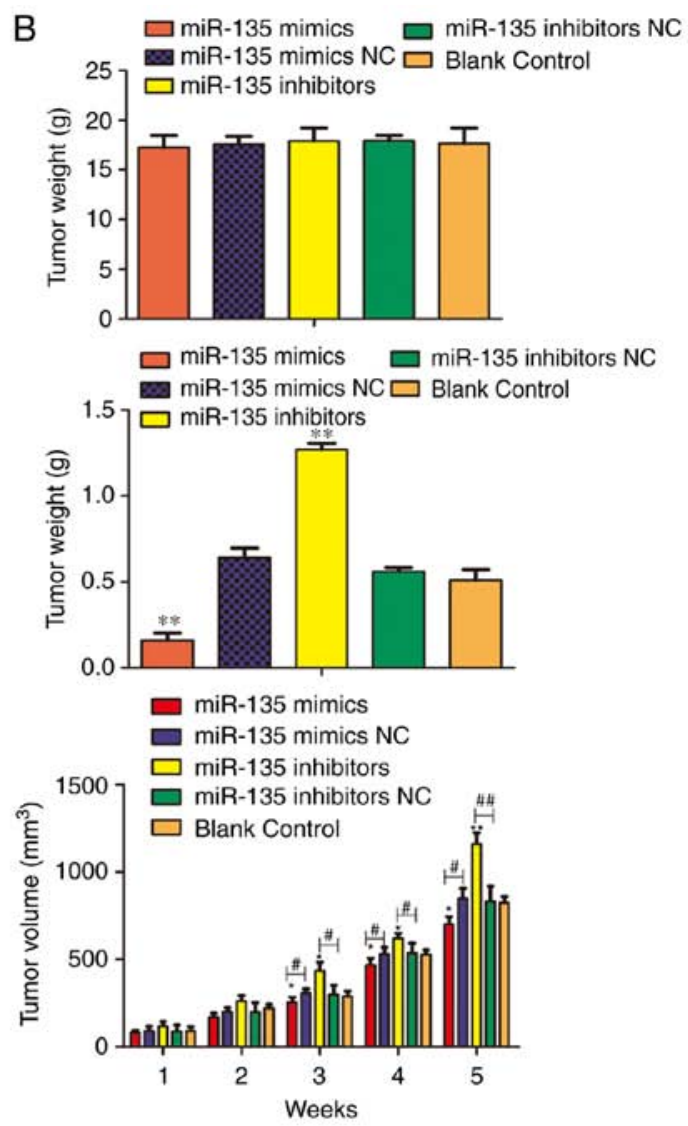

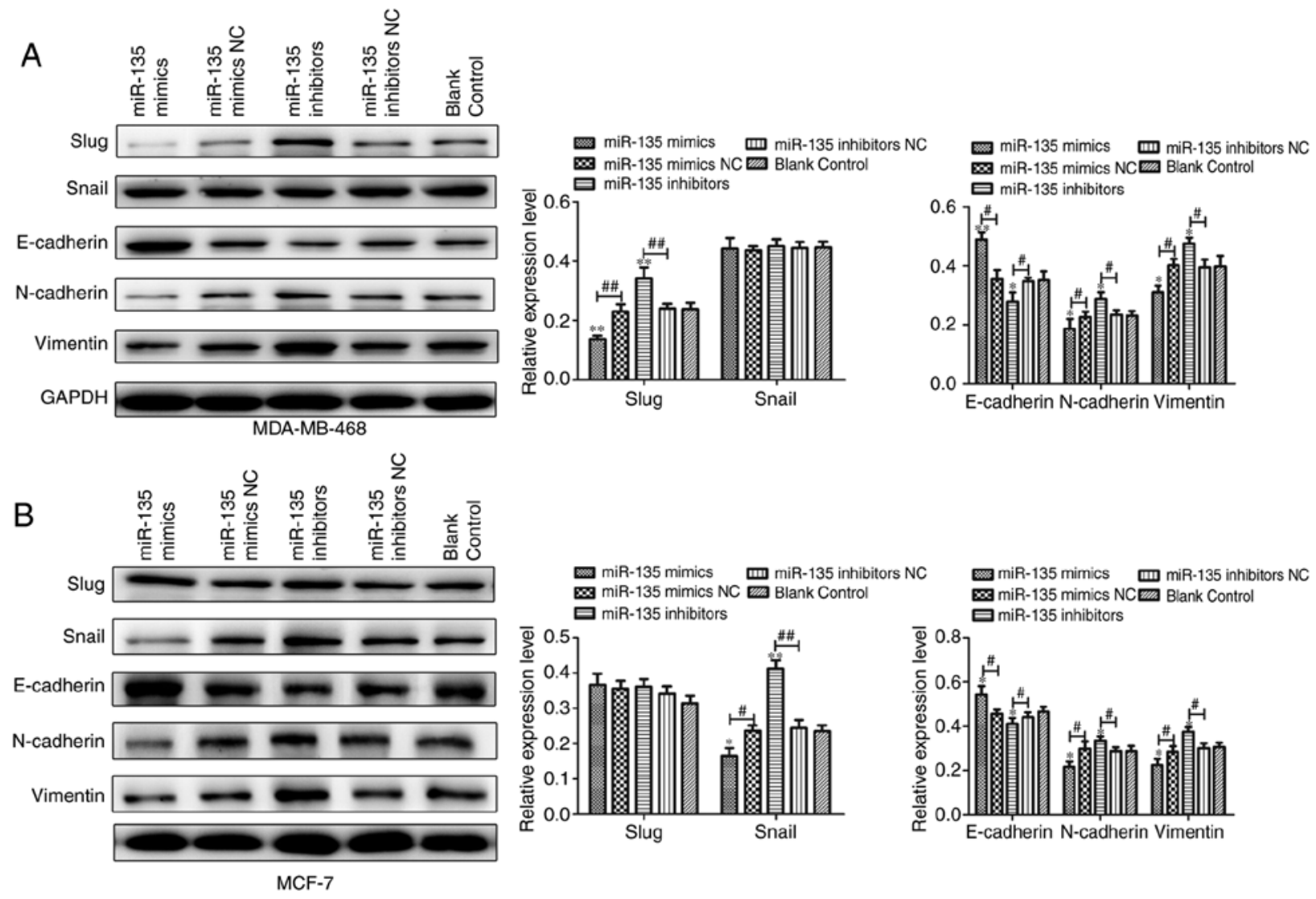

Figure 5. miR-135 inhibits EMT in breast cancer cells. Expression levels of the EMT-associated proteins were determined by western blot assay in (A) MDA-MB-468 and (B) MCF-7 cells. The results were expressed as the mean \pm standard of three independent experiments. ${ }^{*} \mathrm{P}<0.05$ and ${ }^{* *} \mathrm{P}<0.01$ vs. control group. ${ }^{\#} \mathrm{P}<0.05$ and ${ }^{\# \#} \mathrm{P}<0.01$ vs. NC group. NC, negative control; miR, microRNA; EMT, epithelial-mesenchymal transition; $\mathrm{N}$, neural; E, epithelial.

proliferation, migration and invasion ability were stronger than MCF-10A cells.

miR-135 inhibited BC cell proliferation in vitro. To determine the role of miR-135 in regulating cell proliferation, miR-135 mimics, mimics NC, miR-135 inhibitors and inhibitors NC were separately transfected into MDA-MB-468 and MCF-7 cells, respectively. The transfection efficiency of miR-135 was examined by green fluorescent protein (GFP) and RT-qPCR assay. As presented in Fig. 2A and B, cells transfection of miR-135 mimic significantly increased the level of miR-135 $(\mathrm{P}<0.05)$, while miR-135 inhibitors significantly inhibited the expression of miR-135 in MDA-MB-468 and MCF-7 cells $(\mathrm{P}<0.05)$. MTT and colony formation assays were performed to investigate the effect of miR-135 on cell proliferation following transfection for $48 \mathrm{~h}$. As presented in Fig. 2C, the results revealed that the miR-135 inhibitor caused a decrease in optical density, which indicated that the proliferation ability of cells was significantly increased in the miR-135 inhibitor group compared with the control group, while upregulation of the expression of miR-135 attenuated the proliferation of MDA-MB-468 and MCF-7 cells. Furthermore, MDA-MB-468 and MCF-7 cells which transfected miR-135 mimics exhibited fewer and smaller colonies compared with the control cells (Fig. 2D). Taken together, these results revealed that miR-135 overexpression inhibited cell proliferation of $\mathrm{BC}$ in vitro.

miR-135 suppresses the migration and invasion in BC cells. Given that cellular migration and invasion are key processes underlying metastasis, whether miR-135 could affect $B C$ was investigated. To further validate the role of miR-135 in cell migration and invasion in vitro, cell migration and invasion in MDA-MB-468 and MCF-7 cells following transfection with miR-135 mimic NC, miR-135 mimics, miR-135 inhibitor NC and miR-135 inhibitor was determined by wound healing assay and transwell assays. As presented in Fig. 3A, ectopic restoration of miR-135 delayed the migration rate of cells from the wound area, compared with the control group, while miR-135 inhibitor promoted the migration potential of MDA-MB-468 and MCF-7 cells. Transwell assay demonstrated that the migration and invasion capacity of cells transfected with miR-135 mimics was markedly suppressed compared with the control group (Fig. 3B). Moreover, the protein levels of matrix metalloproteinase (MMP)-2 and MMP-9 were examined in MDA-MB-468 and MCF-7 cells. It was demonstrated that miR-135 mimic suppressed the levels of MMP-2 and MMP-9, while the expression of MMP-2 and MMP-9 were remarkably promoted in cells which were transfected with miR-135 inhibitors (Fig. 3C). The results suggested that miR-135 may have the ability to inhibit migration and invasion in $\mathrm{BC}$ cells.

Effects of miR-135 on xenograft tumour growth of breast cancer cells in vivo. To further investigate the role of miR-135 in tumorigenicity of $\mathrm{BC}$ cells in vivo, cells stably transfected with miR-135 mimic, miR-135 inhibitors or controls were injected subcutaneously into nude mice. As presented in Fig. 4A, the tumors formed by the cells which were 

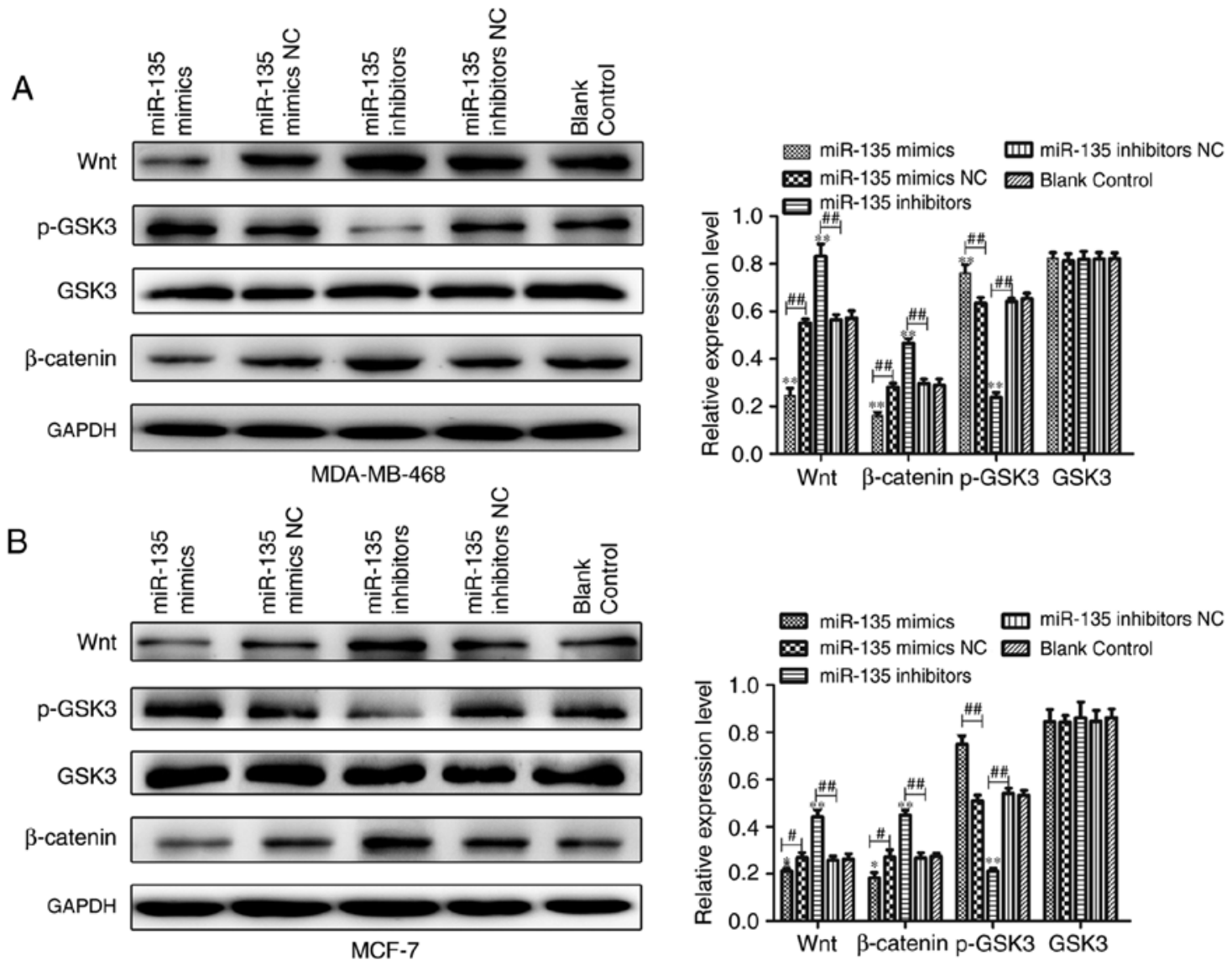

Figure 6. miR-135 inhibited epithelial-mesenchymal transition in breast cancer cells. Western blot analysis of the alterations in the expression of proteins that associated with the Wnt/ $\beta$-catenin signaling pathway in (A) MDA-MB-468 and (B) MCF-7 cells. The results were expressed as the mean \pm standard deviation of three independent experiments. ${ }^{*} \mathrm{P}<0.05$ and ${ }^{* *} \mathrm{P}<0.01$ vs. control group. ${ }^{\#} \mathrm{P}<0.05$ and ${ }^{\# \#} \mathrm{P}<0.01$ vs. NC group. NC, negative control; miR, microRNA; p-GSK, phosphorylated glycogen synthase kinase.

transfected with miR-135 inhibitors were larger and heavier compared with the control tumors. Consistently, miR-135 over-expression significantly inhibited tumor growth of cells of xenografted mice compared with the control $(\mathrm{P}<0.01)$. The tumor sizes were measured every week. Data demonstrates that the tumors in the group injected with cells stably overexpressing miR-135 grew at a slower rate and exhibited smaller volumes compared with the controls. Consistent with the tumor volume, the average tumor weight was also significantly reduced $(\mathrm{P}<0.01$; Fig. $4 \mathrm{~B})$. Furthermore, the subcutaneous tumor tissues were examined by histochemical staining and the effect of miR-135 on the cell apoptosis was assessed by TUNEL assay (Fig. 4C). The results indicated that the degree of apoptosis was notably decreased in cells transfected with miR-135 inhibitor. In addition, overexpression of miR-135 markedly increased the number of apoptotic cells when compared with the control group. Based on these observations, it was demonstrated that miR-135 overexpression inhibited tumor growth in vivo.

miR-135 suppresses EMT and is associated with $W n t / \beta$-catenin signaling activation in $B C$. To identify whether miR-135 can affect cell EMT, the expression of EMT markers in MDA-MB-468 and MCF-7 cells was measured by western blot analysis. It was demonstrated that miR-135 mimic transfection enhanced the expression of E-cadherin and displayed the lower expression of mesenchymal markers including Snail, Slug, neural (N)-cadherin and Vimentin at mRNA and protein levels (Fig. 5) in cells, while the results of cells transfected with miR-135 inhibitors demonstrated the opposite activities. The results of the present study revealed that miR-135 inhibited cells metastasis may be through regulation of EMT in BC cells.

To further elucidate whether miR-135 levels were associated with activation of $\mathrm{Wnt} / \beta$-catenin signaling to regulate-miR-135 inhibited cell EMT, western blotting and immunofluorescence staining assays were performed to detect the proteins levels that were associated with the Wnt/ $\beta$-catenin signaling pathway. As presented in Fig. 6, there was a significant positive association between miR-135 and p-GSK3 expression, but a significant inverse association between miR-135 and Wnt and $\beta$-catenin expression. Furthermore, immunofluorescence staining observed similar results (Figs. 7 and 8). The levels of Wnt and $\beta$-catenin were remarkably upregulated in miR-135 inhibitors group compared with the control group. In contrast, overexpression of miR-135 increased the levels of phosphorylated (p)-glycogen synthase kinase (GSK)3. Therefore, the aforementioned findings indicate that downregulation of miR-135 participates in the regulation of cell biological functions, at least in part through activating $\mathrm{Wnt} / \beta$-catenin signaling in BC. 

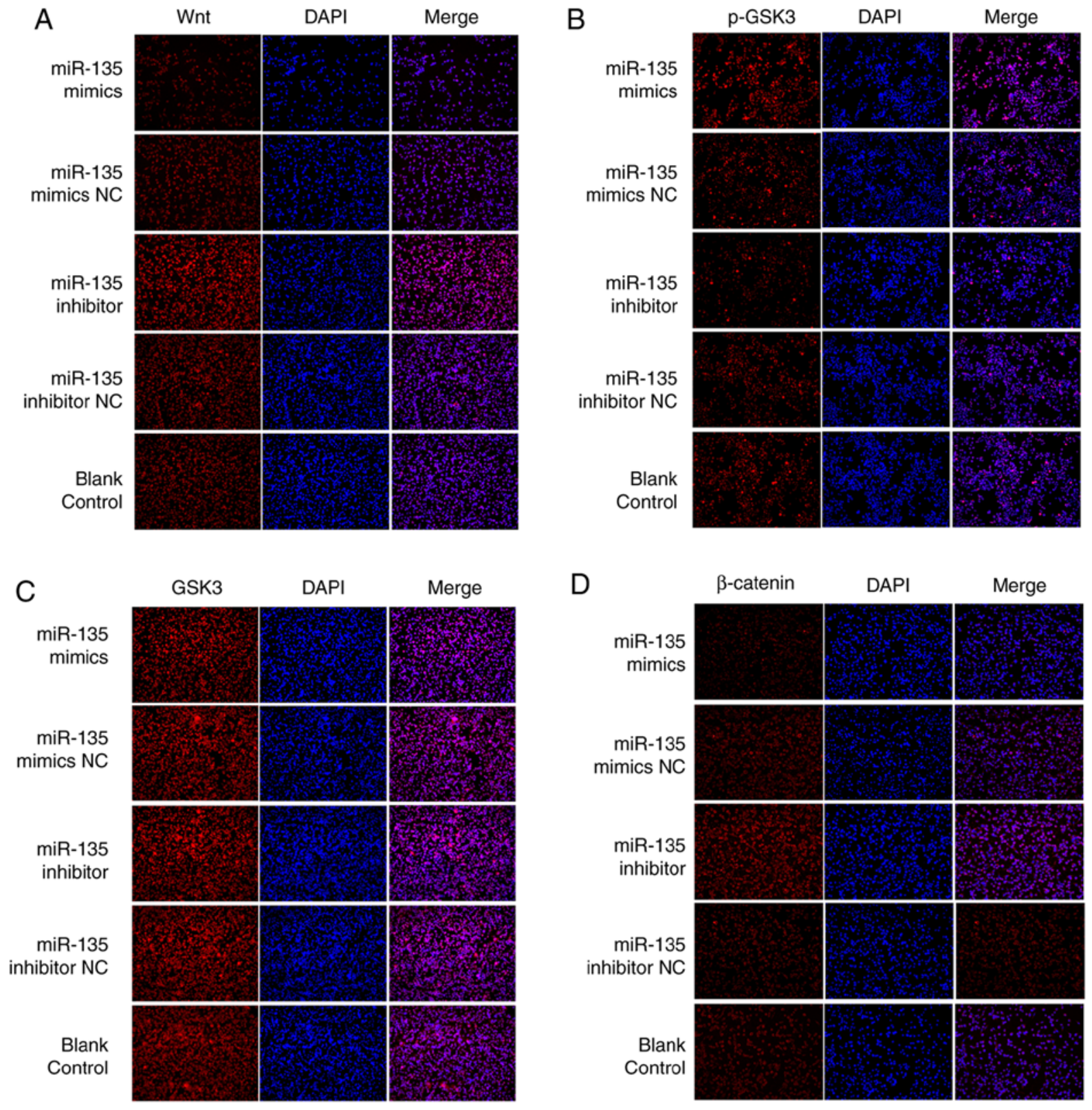

MDA-MB-468

Figure 7. miR-135 inhibits the epithelial-mesenchymal transition which is associated with the activation of Wnt/ $\beta$-catenin signaling. Immunofluorescence analysis of the alterations in the expression of (A) Wnt, (B) p-GSK3, (C) GSK3 and (D) $\beta$-catenin in MDA-MB-468 cells. NC, negative control; miR, microRNA; p-GSK, phosphorylated glycogen synthase kinase.

\section{Discussion}

$\mathrm{BC}$ is the most frequent cancer of women due to a complicated etiology involving environmental and genetic factors. miRNAs, as the class of endogenous non-coding small RNA and can modulate a wide variety of biological processes including tumor cell proliferation, differentiation, migration, invasion, apoptosis and metastasis (32-35). Numerous miRNAs have been reported to be abnormally expressed in $\mathrm{BC}$ cells and tissues (36). However, the role of miR-135 in BC remains elusive.

The present study identified the decreased expression of miR-135 in MDA-MB-468, MDA-MB-231 and MCF-7 compared with breast epithelial cell line MCF-10A. Therefore it was inferred that miR-135 may act a tumor suppressor involved in the progression and development in BC. Xu et al reported (21) that miR-135 inhibits prostate cancer cell growth and migration by targeting EGFR. Wu et al (37) demonstrated that miR-135a targets JAK2 and inhibits gastric cancer cell proliferation. The hypothesis was further confirmed by in vitro and in vivo analysis in MDA-MB-468 and MCF-7 cells with MTT, colony formation, wound healing, transwell and xenograft tumor growth assays. The results demonstrated that overexpression of miR-135 inhibited the proliferation, migration, invasion and tumorigenicity.

A number of studies have demonstrated that tumor invasion and metastasis are a series of complex processes and MMPs are associated with tumor invasion and metastasis (38-40). 
A
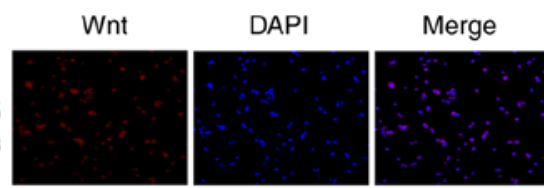

miR-135
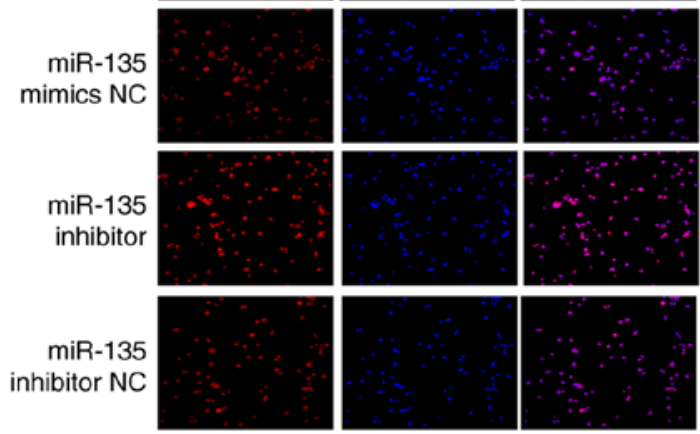

Control
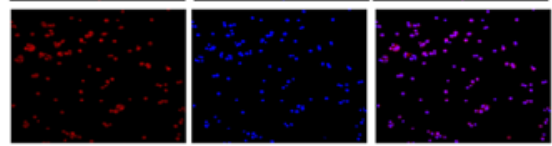

C

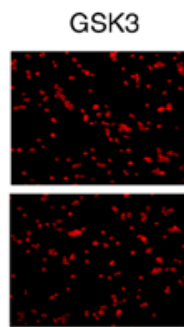

miR-135
mimics

miR-135
mimics NC mimics $\mathrm{NC}$
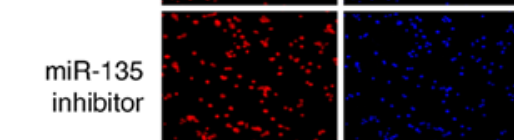

miR-135 inhibitor NC
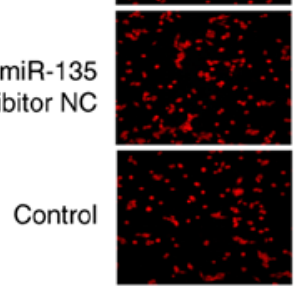
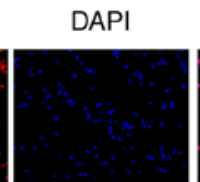

Merge
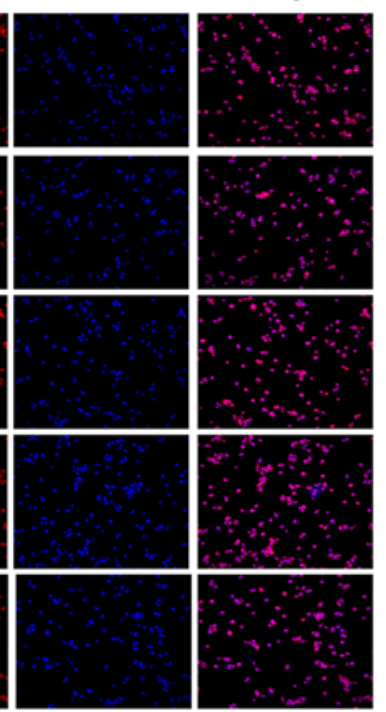

B

$$
\text { miR-135 }
$$
mimics

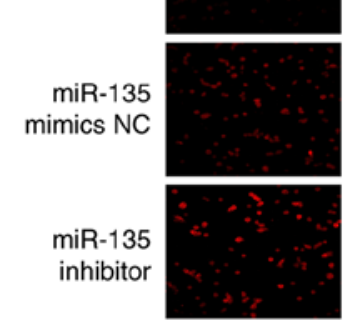

miR-135

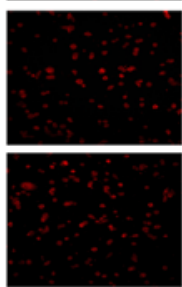

D

p-GSK3

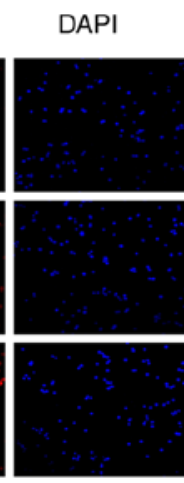

Merge

inhibitor NC
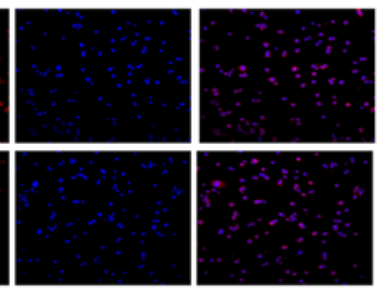

$\beta$-catenin

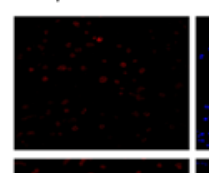

DAPI

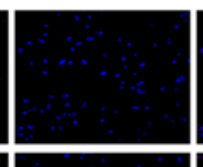

Merge

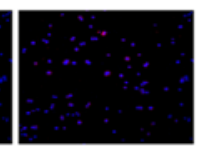

miR-135 mimics NC
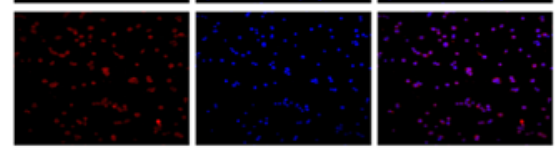

miR-135
inhibitor
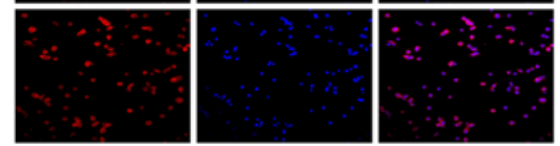

miR-135 inhibitor NC
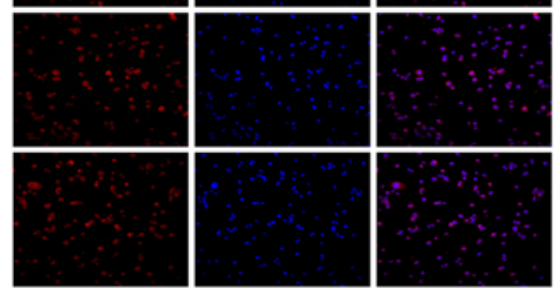

MCF-7

Figure 8. miR-135 inhibits the epithelial-mesenchymal transition which is associated with the activation of Wnt/ $\beta$-catenin signaling. Immunofluorescence analysis of the alterations in the expression of (A) Wnt, (B) p-GSK3, (C) GSK3 and (D) $\beta$-catenin in MCF-7 cells. NC, negative control; miR, microRNA; p-GSK, phosphorylated glycogen synthase kinase.

In the present study, the data demonstrated that MMP-2 and MMP-9 expression was promoted following transfection with miR-135 inhibitors, while miR-135 mimics could suppress the expression of MMP-2 and MMP-9. The role of EMT has been paid more attention in tumor metastasis as EMT is a complex process in which epithelial cells lose their epithelial morphology and acquire a mesenchymal phenotype $(41,42)$. Therefore, it was demonstrated that miR-135 could inhibit the EMT process by inducing the levels of E-cadherin and reducing Slug, Snail, N-cadherin and Vimentin expression. The Wnt/ $\beta$-catenin signaling pathway has a significant impact on the maintenance of stem cell properties and cancer metastasis $(43,44)$. Additionally, the nuclear accumulation of $\beta$-catenin is a crucial step in the activation of the Wnt signaling pathway (45). In the present study, evidence was provided that miR-135 could inhibit the activation of the $\mathrm{Wnt} / \beta$-catenin pathway.
From these data, it was demonstrated that miR-135 could inhibit cell proliferation, migration and invasion, at least in part through Wnt/ $\beta$-catenin signaling pathway in BC. It was concluded that miR-135 was a potential tumor suppressor and could serve a critical role in the progression of BC. In conclusion, the results of the present study could represent a potential therapeutic target for the diagnosis and treatment of breast cancer. Furthermore, the present study provides novel insights into the pathogenesis and therapeutics of breast cancer. The current study is a preliminary study on the anti-tumor effect of miR-135 in BC. Previous studies have reported that signal transducer and activator of transcription (STAT)3 is connected with the nuclear factor (NF)- $\kappa$ B signaling pathway (46-49). The association between miR-135 and the STAT3/NF- $\kappa$ B signaling pathway on $\mathrm{BC}$ based on current findings will be investigated in future studies. 


\section{Acknowledgements}

Not applicable.

\section{Funding}

No funding was received.

\section{Availability of data and materials}

The datasets used during the present study are available from the corresponding author upon reasonable request.

\section{Authors' contributions}

DJ and HC conceived and designed the study. BZ and YX performed the experiments. DJ wrote the manuscript. All authors have read and approved the manuscript and agree to be accountable for all aspects of the research in ensuring that the accuracy and integrity of any part of the work are appropriately investigated and resolved.

\section{Ethics approval and consent to participate}

Animal care and use were carried out according to the ethical guidelines by Nanjing Medical University Animal Care and Use Committee and approved by the Nanjing Medial University Experimental Animal Ethics Committee and the permit number is $\mathrm{SYXK}(\mathrm{su}) 2016-0016$.

\section{Patient consent for publication}

Not applicable.

\section{Competing interests}

The authors declare they have no competing interests.

\section{References}

1. Siegel RL, Miller KD and Jemal A: Cancer statistics, 2015. CA Cancer J Clin 65: 5-29, 2015.

2. Ismail NI, Kaur G, Hashim H and Hassan MS: S100A4 overexpression proves to be independent marker for breast cancer progression. Cancer Cell Int 8: 12, 2008.

3. Fedewa SA, Sauer AG, Siegel RL and Jemal A: Prevalence of major risk factors and use of screening tests for cancer in the United States. Cancer Epidemiol Biomarkers Prev 26: 1192-1208, 2017.

4. Zou DH, He XM, Chen B, Xu XH, Zhang XP, Ni JF and Mao WM: Expression and association of reproductive hormones and receptors in postmenopausal patients with breast cancer. Eur J Gynaecol Oncol 38: 727-732, 2017.

5. Chaffer CL and Weinberg RA: A perspective on cancer cell metastasis. Science 331: 1559-1564, 2011.

6. Rivera E and Gomez H: Chemotherapy resistance in metastatic breast cancer: The evolving role of ixabepilone. Breast Cancer Res 12(Suppl 2): S2, 2010.

7. Lorusso $G$ and Rüegg C: The tumor microenvironment and its contribution to tumor evolution toward metastasis. Histochem Cell Biol 130: 1091-1103, 2008.

8. Gromak N: Intronic microRNAs: A crossroad in gene regulation. Biochem Soc Trans 40: 759-761, 2012.

9. Fernandez S, Risolino M, Mandia N, Talotta F, Soini Y, Incoronato M, Condorelli G, Banfi S and Verde P: miR-340 inhibits tumor cell proliferation and induces apoptosis by targeting multiple negative regulators of p27 in non-small cell lung cancer. Oncogene 34: 3240-3250, 2015.
10. Sandhu R, Rein J, D'Arcy M, Herschkowitz JI, Hoadley KA and Troester MA: Overexpression of miR-146a in basal-like breast cancer cells confers enhanced tumorigenic potential in association with altered p53 status. Carcinogenesis 35: 2567-2575, 2014.

11. Waning DL, Mohammad KS and Guise TA: Cancer-associated osteoclast differentiation takes a good look in the miR(NA)ror. Cancer Cell 24: 407-409, 2013.

12. Valeri N, Braconi C, Gasparini P, Murgia C, Lampis A, Paulus-Hock V, Hart JR, Ueno L, Grivennikov SI, Lovat F, et al: MicroRNA-135b promotes cancer progression by acting as a downstream effector of oncogenic pathways in colon cancer. Cancer Cell 25: 469-483, 2014.

13. Ma Y, Zhang P, Wang F, Zhang H, Yang Y, Shi C, Xia Y, Peng J, Liu W, Yang Z and Qin H: Elevated oncofoetal miR-17-5p expression regulates colorectal cancer progression by repressing its target gene P130. Nat Commun 3: 1291, 2012.

14. Wang B, Wang H and Yang Z: MiR-122 inhibits cell proliferation and tumorigenesis of breast cancer by targeting IGF1R. PLoS One 7: e47053, 2012.

15. Li L, Yuan L, Luo J, Gao J, Guo J and Xie X: MiR-34a inhibits proliferation and migration of breast cancer through down-regulation of Bcl-2 and SIRT1. Clin Exp Med 13: 109-117, 2013.

16. Sun Y, Wang M, Lin G, Sun S, Li X, Qi J and Li J: Serum microRNA-155 as a potential biomarker to track disease in breast cancer. PLoS One 7: e47003, 2012.

17. Nagel R, le Sage C, Diosdado B, van der Waal M, Oude Vrielink JA, Bolijn A, Meijer GA and Agami R: Regulation of the adenomatous polyposis coli gene by the miR-135 family in colorectal cancer. Cancer Res 68: 5795-5802, 2008.

18. Holleman A, Chung I, Olsen RR, Kwak B, Mizokami A, Saijo N, Parissenti A, Duan Z, Voest EE and Zetter BR: miR-135a contributes to paclitaxel resistance in tumor cells both in vitro and in vivo. Oncogene 30: 4386-4398, 2011.

19. Yamada Y, Hidaka H, Seki N, Yoshino H, Yamasaki T, Itesako T, Nakagawa $\mathrm{M}$ and Enokida $\mathrm{H}$ : Tumor-suppressive microRNA-135a inhibits cancer cell proliferation by targeting the c-MYC oncogene in renal cell carcinoma. Cancer Sci 104: 304-312, 2013.

20. Chen Y, Zhang J, Wang H, Zhao J, Xu C, Du Y, Luo X, Zheng F, Liu R, Zhang H and Ma D: miRNA-135a promotes breast cancer cell migration and invasion by targeting HOXA10. BMC Cancer 12: 111, 2012.

21. Xu B, Tao T, Wang Y, Fang F, Huang Y, Chen S, Zhu W and Chen M: hsa-miR-135a-1 inhibits prostate cancer cell growth and migration by targeting EGFR. Tumour Biol 37: 14141-14151, 2016.

22. Thiery JP, Acloque H, Huang RY and Nieto MA: Epithelial-mesenchymal transitions in development and disease. Cell 139: 871-190, 2009.

23. Xu WH, Liu ZB, Yang C, Qin W and Shao ZM: Expression of dickkopf-1 and beta-catenin related to the prognosis of breast cancer patients with triple negative phenotype. PLoS One 7: e37624, 2012

24. Lópezknowles E, Zardawi SJ, McNeil CM, Millar EK, Crea P, Musgrove EA, Sutherland RL and O'Toole SA: Cytoplasmic localization of beta-catenin is a marker of poor outcome in breast cancer patients. Cancer Epidemiol Biomarkers Prev 19: 301-309, 2010.

25. Zardawi SJ, O'Toole SA, Sutherland RL and Musgrove EA: Dysregulation of Hedgehog, Wnt and Notch signalling pathways in breast cancer. Histol Histopathol 24: 385-398, 2009.

26. He X: Understanding Wnt/b-catenin signaling in development and cancer. J Nanjing Med Univ 22: 80, 2008.

27. Clevers H: Wnt/beta-catenin signaling in development and disease. Cell 127: 469-480, 2006.

28. Chen Q, Cao HZ and Zheng PS: LGR5 promotes the proliferation and tumor formation of cervical cancer cells through the Wnt/B-catenin signaling pathway. Oncotarget 5: 9092-9105, 2014.

29. Hua HW, Jiang F, Huang Q, Liao Z and Ding G: MicroRNA-153 promotes $\mathrm{Wnt} / \beta$-catenin activation in hepatocellular carcinoma through suppression of WWOX. Oncotarget 6: 3840-3847, 2015.

30. Zhou DS, Wang HB, Zhou ZG, Zhang YJ, Zhong Q, Xu L, Huang YH, Yeung SC, Chen MS and Zeng MS: TACC3 promotes stemness and is a potential therapeutic target in hepatocellular carcinoma. Oncotarget 6: 24163-24177, 2015.

31. Livak KJ and Schmittgen TD: Analysis of relative gene expression data using real-time quantitative PCR and the 2(-Delta Delta C(T)) method. Methods 25: 402-408, 2001. 
32. Zhang B, Wang Q and Pan X: MicroRNAs and their regulatory roles in animals and plants. J Cell Physiol 210: 279-289, 2007.

33. Garzon R, Calin GA and Croce CM: MicroRNAs in cancer. Ann Rev Med 60: 167-179, 2015.

34. Lu J, Getz G, Miska EA, Alvarez-Saavedra E, Lamb J, Peck D, Sweet-Cordero A, Ebert BL, Mak RH, Ferrando AA, et al: MicroRNA expression profiles classify human cancers. Nature 435: 834-838, 2005.

35. Miranda KC, Huynh T, Tay Y, Ang YS, Tam WL, Thomson AM, Lim B and Rigoutsos I: A pattern-based method for the identification of MicroRNA binding sites and their corresponding heteroduplexes. Cell 126: 1203-1217, 2006.

36. Shi W, Gerster K, Alajez NM, Tsang J, Waldron L, Pintilie M, Hui AB, Sykes J, P'ng C, Miller N, et al: MicroRNA-301 mediates proliferation and invasion in human breast cancer. Cancer Res 71: 2926-2937, 2011.

37. Wu H, Huang M, Cao P, Wang T, Shu Y and Liu P: MiR-135a targets JAK2 and inhibits gastric cancer cell proliferation. Cancer Biol Ther 13: 281-288, 2012.

38. Bar-Or A, Nuttall RK, Duddy M, Alter A, Kim HJ, Ifergan I, Pennington CJ, Bourgoin P, Edwards DR and Yong VW: Analyses of all matrix metalloproteinase members in leukocytes emphasize monocytes as major inflammatory mediators in multiple sclerosis. Brain 126: 2738-2749, 2003.

39. Westermarck J and Kähäri VM: Regulation of matrix metalloproteinase expression in tumor invasion. FASEB J 13: 781-792, 1999.

40. Kraiem Z and Korem S: Matrix metalloproteinases and the thyroid. Thyroid 10: 1061-1069, 2000.

41. Kalluri R and Weinberg RA: The basics of epithelial-mesenchymal transition. J Clin Invest 119: 1420, 2009.

42. Kalluri R and Neilson EG: Epithelial-mesenchymal transition and its implications for fibrosis. J Clin Invest 112: 1776-1784, 2003.
43. Leung CO, Mak WN, Kai AK, Chan KS, Lee TK, Ng IO and Lo RC: Sox 9 confers stemness properties in hepatocellular carcinoma through Frizzled-7 mediated Wnt/ $\beta$-catenin signaling. Oncotarget 7: 29371-29386, 2016.

44. Yuan X, Sun X, Shi X, Wang H, Wu G, Jiang C, Yu D, Zhang W, Xue B and Ding Y: USP39 promotes colorectal cancer growth and metastasis through the Wnt/ $\beta$-catenin pathway. Oncol Rep 37: 2398-2404, 2017

45. Mao Y, Xu J, Li Z, Zhang N, Yin H and Liu Z: The role of nuclear $\beta$-catenin accumulation in the Twist2-induced ovarian cancer EMT. PLoS One 8: e78200, 2013.

46. Yamamoto $\mathrm{Y}$ and Gaynor RB: Therapeutic potential of inhibition of the NF- $\mathrm{BB}$ pathway in the treatment of inflammation and cancer. J Clin Invest 107: 135-142, 2001.

47. Takaesu G, Surabhi RM, Park KJ, Ninomiya-Tsuji J, Matsumoto K and Gaynor RB: TAK1 is critical for IkappaB kinase-mediated activation of the NF-kappaB pathway. J Mol Biol 326: 105-115, 2003.

48. Sasaki CY,Barberi TJ, Ghosh PandLongo DL: Phosphorylation of RelA/p65 on serine 536 defines an I $\{$ kappa $\}$ B \{alpha\}-independent NF-\{kappa\}B pathway. J Biol Chem 280: 34538-34547, 2005.

49. Wajant $H$ and Scheurich P: TNFR1-induced activation of the classical NF-кB pathway. FEBS J 278: 862-876, 2015.

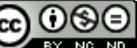

This work is licensed under a Creative Commons Attribution-NonCommercial-NoDerivatives 4.0 International (CC BY-NC-ND 4.0) License. 